\title{
Challenges in Mining Industry and Addressing through Research and Innovation
}

\author{
${ }^{1}$ V. M. S. R. Murthy, ${ }^{\text {2}}$ M. S. Tiwari, ${ }^{3}$ A. K. Raina \\ ${ }^{1}$ Department of Mining Engineering, Indian Institute of Technology (Indian School of Mines), Dhanbad-826004 \\ ${ }^{2}$ Department of Civil Engineering, Shri Ramdeobaba College of Engineering and Management, Nagpur - 440013 \\ ${ }^{3}$ CSIR-CIMFR, Nagpur \\ Email:vmsrmurty@iitism.ac.in,tiwarims@rknec.edu,rainaji@gmail.com
}

Received: 18th November 2019, Accepted: 31st January 2020, Published: 29th February 2020

\begin{abstract}
Indian economy is growing at a fast pace and the mining industry has to support the supply of minerals, metals and energy to sustain the growth rate. A plan needs to be devised which address issues raised by steep production demands as current system will be unable to provide solutions. Integration of various components of mining like innovative technology, instrumentation, data analysis, suitable changes in curriculum of academia and training facilities etc. are needed to meet the challenges. A system approach with participation of all stake holders is needed wherein every component is converted to a state of art unit so as to provide solutions to problems in their respective domains. Mining industry, service providers like machinery and explosive manufacturers, R \& D institutions and academia has to work in harmony to achieve the goals.
\end{abstract}

Keywords

Economy, Growth Rate, Integration, System Approach, State of Art, Harmony

\section{Introduction}

Challenges in mining industry are growing rapidly considering the steep production requirements and growing environmental and safety concerns. To address these issues current mining methods, technology and management needs to be revisited. New innovations in mining technology backed by advanced instrumentation and their seamless integration in mine design and operations, is the only way to meet the current challenges. This paper highlights some of the key challenges in surface and underground mining and suggests the research and innovation requirements for achieving productive and safe mining.

\section{Methodology for Surface Mining}

Surface mining contributes majority of coal produce and the challenges of planning, design, operation and management of large scale opencast projects involves adaptation of new mining technology, software and management. Some of the key surface mining issues that require immediate attention along with possible direction are discussed.

\section{Land Acquisition}

The land acquisition problem to some extent can be solved by the deployment of high angle conveyor in mines. This is ideal for both mining and industrial applications, including handling of wet or sticky materials and an ideal option for steep angle applications in deep mines. In this, pressing components secure material toward center of belt, sealing the belt edges together. This system uses standard idlers and rollers for quick and easy component replacement. This has flexibility to be shortened or lengthened or has the conveying angle altered for a new location apart from being mobile.

\section{Mass Production using Surface Miner}

Surface miner has a wide applicability in projects where drilling and blasting is prohibited, thus improves coal recovery in such areas which are sensitive to blasting operations. It can be conveniently used for mining of coal and overburden. This machine can cut the slices upto $10 \mathrm{~cm}$. It has a wide applicability in extracting coal seams having any number of intermittent dirt bands aiding clean mining. This machine can be worked in coal seams having gradient upto 1 in 4 . A DST funded R\&D project is in progress at IIT(ISM) in collaboration with L\&T for drum design in varied geology as well as mining method design for selective mining and waste disposal.

\section{Dump Planning}

Dump planning has assumed critical proportion due to lesser space available for dumping particularly in case of deep and large opencast projects. The height and width of the dump shall be properly selected to ensure safety in equipment operations and also keeping in view the production. Use of modern mine planning tools and software with adequate training is the need of the hour. Some of the Computer aided mine planning design software relevant in this context are Minex, Haulsim, Dragsim, etc. Height and width of dump depends on following factors:

- Cohesion of dump material

- Angle of internal friction

- Cohesion of foundation material

- Angle of internal friction in foundation material 
- Ground acceleration on dump generated due to blasting

- Distance of toe of external dump from nearest surface edge of quarry

A proper dump planning by keeping above factors in mind can save space.

4. Water Management

One of the main reasons for excess of water in a surface mine is rainfall. This excess of water will affect the productivity of mine and also affects the slope stability. The mine management has to overcome the issues of mine flood control, mine drainage, and the prevention of surface and ground water pollution. Mine water management is dynamic and has to change as conditions and mine plans change. It is essential to understand this and provide the resources throughout the life of a mine to deal with water issues.

\section{Stability of Slopes and Dumps}

Slope stability is a critical safety and production issue for coal mines. Designing stable bench and dump slopes can be done using software namely Dip, Galena, Slope etc. A common technique to determine slope stability is to monitor the small precursory movements, which occur prior to collapse. The real-time display of the movement of mine walls has allowed continuous management of the risk of slope instability at a mine operations level. The 'slope stability radar (SSR)' has been developed to remotely scan a rock slope to continuously monitor the spatial deformation of the face. Broad area coverage and almost real time scanning means that large areas of slope (e.g. $500,000 \mathrm{~m}^{2}$ ) can be scanned and results are obtained in less than 10 minutes. Successful use of this technique is already demonstrated in mines and many large opencast mines are resorting to this. [7]

\section{Rock Fragmentation and Ground Vibration}

Fragmentation control through effective blast design and its effect on productivity are the challenging tasks for practicing blasting engineer. Fragmentation will affect all the other associated sub-systems, i.e. loading, transport, crushing and milling operations. In opencast mining, where blasting is employed for excavation, the overall cost effectiveness of the production operations is compatible with optimization of drilling and blasting parameters.Key factors affecting fragmentation need to be identified as equipment productivity is significantly influenced by rock fragmentation.Vibration is also one of the main issues during blasting in surface mines. The problem can be controlled by the use of electronic detonators. Use of software like Fragalyst and Wipfrag/Wipjoint for the analysis of fragmentation and other blast design software such as JKSimblast, Shotplus, I Blast, for blast design can help overcome the above stated issues.

\section{Asset Management}

The assets, ranging from smart drillers and loaders to self-driving trucks, are becoming the bulk of the equipment today. A few younger and trained workers are expected to fill the gap thusmaking mining operations more reliant on their machinery and technology management tools. Key challenge here is how the huge data generated is handled. Use of Big Data and AI applications is the need of the hour and software firms like IBM have already mobilised the required software and skill sets with use cases. The key objective is to limit the downtime created when a key asset is down. [1]

\section{Computerised Mine Planning}

The computer has made a significant impact on mine planning and design. Computer systems are now available to emulate existing planning techniques and also to perform what were once manually difficult tasks. Computerised mine planning includes reserve estimation, layout evaluation and equipment selection and scheduling. The software which can be used is Minex, Surpac, Whittle, Vulcan, DataMine, etc. In contemporary practice the application of mining computer program is significantly expanded and it can be concluded that the computer aided design has become a common way of developing mining projects. [3]

\section{Technological Upgradation of Human Resources}

Human resource management is an organizational function that deals with the people and issues related to people such as compensation, hiring, performance management, and training. There is the need for effective management of human resources irrespective of the size and nature of the organization. [10] Human resource management relates to the total set of knowledge, skills and attitudes that firms need to compete. It involves concern for and action taken in the management of people. This also deals with issues like recruitment and selection, training and development, wage and salary administration, performance appraisal etc.

\section{Methodology for Underground Mining}

Underground mining is going to play a major role in meeting the future production requirementsconsidering the growing limitations of surface mining technology, namely, environment management and land availability apart from other factors. Some of the key issues needing immediate attention are discussed below:

\section{Mineral Exploration for Advanced Mining Technology}

Delineation of mineable reserves with greater confidence, their continuity and structural anomalies are the key for successful selection and operation of advanced mining technology more specifically in underground mining. Modern mineral exploration has been driven largely by technology. Many mineral discoveries since the 1950s can be attributed to geophysical and geochemical technologies developed by both industry and government. GPS, GIS, Radar interferometry and other techniques were newly applied to mineral exploration. Research in basic geological 
sciences, geophysical and geochemical methods, and drilling technologies could improve the effectiveness and productivity of mineral exploration.

\section{Rock Cuttability Assessment and Machine Selection}

"Cuttability" of rock depends on a number of influencing parameters. These parameters can be categorized as rock/rockmass parameters, machine parameters and the type of application. Cuttability assessment will lead to a proper selection of bits for shearers, continuous miners, surface miners and other mining machines.This assessment can also help in the increment of life of a machine and economy of operation.

\section{Strata Control}

Strata control utilizes various techniques to prevent or control failure of the strata around mine openings at least for the period where access is required. Deployment of trained set of personnel in designated roles at mine itself is the requirement today. The people involved in front face mining operations must be associated with this activity. Area wise strata control shall be established for the testing and monitoring of strata in UG mines.In order to analyse strata reactions, properties such as strength (tensile and compressive), modulus of elasticity, Poisson's ratio, etc are required, along with details of the likely stress fields to which they will be subjected. In bord and pillar mining orientation of mine, galleries oblique to major joints or weakness planes can reduce the impact of strata control issues if not avoided completely. Longwall entries also have been successfully oriented in SCCL where the stress fields are clearly defined. [8]

\section{Development in Roof Bolting}

One of the key missing and vital technology link in mechanized mine development with the deployment of continuous miner/road header is roof bolting to match the fast advancing face. The use of bolter-miner will lead to faster advance rate of face. The unsupported area will be minimum while using a mechanised bolting. The mines, namely, Jhanjhra and Moonidih have already deployed bolter-miners, but their proportion needs to increase.Less unsupported area will give more stability to the surrounding rockmass and thus helps in achieving a better strata control. Use of mechanised roof bolter will helps in automatic grouting, bolting, uniform application of torque, reduced manpower, fast rate of bolting and enhanced safety.

\section{Underground Coal Mining Technology-The Scaling Up}

The latest technological developments in underground mining are:

- Double ended ranging drum (DERD) shearer - Longwall Mining

- Continuous miner/ Road header for mine development

- Mechanised roof bolter

- Hydraulic face drilling rig

- Environmental tele-monitoring system

The above upgradation will lead to high production, high rate of advance and higher productivity.

\section{Controlled Blasting and Induced Blasting of Strong Roof}

Blasting-off-solid for longer pulls and in weaker roofs requires suitable charge and blast designs for improved productivity and safety. Management of hard roof has been another daunting task in majority of bord and pillar and longwall mining methods. Use of controlled induced blasting has been largely successful in managing such cases. Blasting gallery in Gassy I mines can be revisited where spontaneous heating and roof management are not critical. [2]

\section{Goaf Edge Supports}

At present, the support at the goaf edge during liquidating the standing pillars or in regular depillaring operations in coalmines consists of cogs and props made of timber and steel. Much of the timber cannot be re-cycled and need to be replaced before the next round of support is erected. This leads to high timber consumption and cost of per ton of coal extracted from the mine. Another disadvantage of the existing practice is that the labour intensive nature of erecting and dismantling timber and steel cogs and props. The above disadvantages are effectively eliminated by employing SAGES and ABLS in UG mines. SAGES an indigenous development has been successfully deployed in BCCL and SCCL. Currently, IIT(ISM) and APHMEL are jointly developing a 500 tonne capacity SAGES after successful trials of 200 tonne capacity SAGES 200 in association with M/s Jai Bharat Equipment Ltd.

\section{Rock Mechanics and Mining Instrumentation}

\section{Planning, Modelling, Rock/Rockmass Characterisation}

This includes site characterisation, laboratory testing, field testing, deformability tests, In situ stress measurements, Geophysical testing (shallow seismic refraction), bolting and anchoring tests and monitoring. Slim borehole scanner, refraction seismic tomography, cavity scanning, ground probing radar have been successfully used for mapping the competence of subsurface strata and designing efficient excavations in rockmass. [4]

\section{VOD Measurement}

Velocity of Detonation (VOD) is an important characteristic parameter of explosive material. The performance of explosive invariably depends on the velocity of detonation. The power/ strength of explosive to cause fragmentation of the solid rock determine the efficiency of the Blast performed. It is an established fact that measuring velocity of detonation gives a good indication of the strength and hence the performance of the explosive. VOD measurement techniques such as electric, nonelectric and fibre optic can be used. [9] 


\section{Near and Far-field Ground Vibration Analysis}

Ground vibration control for reducing its impact on surrounding structures as well as rock has been one of the key areas of research since long. With the advent of advanced instrumentation such as near-field sensors (accelerometers, high-frequency sensors- seismic and acoustic) it has become possible to undertake large scale blasts in large opencast mines by control the same within permissible limits of structures. Backbreak control in blasting faces also has been possible for effective bench stability and reduced loss of explosive energ5.5 Fractured propagation in brittle rocks

\section{Acoustic Emission to detect the Rock Fracture Propagation}

Acoustic emission (AE) is the phenomenon of radiation of acoustic (elastic) waves in solids that occurs when a material undergoes irreversible changes in its internal structure. Its application has grown extensively in assessing the rock failures in deep settings.

\section{In situ Stress Measurement}

All in situ measurement techniques consists of disrupting the rock. The response associated with disturbance is measured and analysed. The main methods used for the measurement of in situ stress are hydrofracturing method, borehole relief methods and surface relief methods. Designing coal pillars considering in situ stresses particularly in deeper mines is the need of the hour. Needful instrumentation and use is increasing. Monitoring of sub-surface strata movement is another area which is necessary for strata data dilation under varied stress environment (virgin and mining induced). This could be used in method design and extraction sequencing. [6]

\section{Specific Energy Studies and Cutting Drum Design}

This is another area of research. IIT(ISM) in collaboration with L\&T is undertaking a research project funded by DST under clean mining technology initiative (CCORD2017). This is based on already conducted investigations for estimating cutting performance, diesel and pick consumption while cutting in varied rock settings. [5]

\section{New National Research and Training Facilities 1. Virtual Reality Mine Simulators}

Use of virtual reality and augmented reality has a great potential to give a true immersion in the mining environment thus enabling the technology seeker and provider an excellent tool to effectively communicate the challenges and also prepare the incumbent with needful skill sets in different scenarios. Though equipment simulators are being used in different mines and establishments still there is no mine simulator where in the entire mine setting can be captured alongwith equipment, and people involved in different operational environment. One such setup with a $360^{\circ}$ Theatre is in the process of development at IIT(ISM) Dhanbad with the funding from CIL R\&D.

\section{Gas and Dust Explosion Simulators for Coal Mines}

Considering the growing production needs and the expected rise of share from underground mining it is necessary to develop adequate research capabilities in assessing the gas and dust explosion proneness in mines which are highly gassy as well as mining friable coals. Spontaneous heating of coals, gas evolution characteristics, propensity of gas and dust to explosion coupled development of re-entry protocols is the need of the hour. IIT(ISM) is establishing a state-of-the-art lab under a joint R\&D project with CSIR-CIMFR. This is also funded by CIL R\&D.Both these national facilities are under the Indo-Australian joint initiative with Simtars as Australian Partner and CIL with its subsidiaries as Indian Partner under the direction of Ministry of Coal, Govt. of India and are expected to start by end of 2020 .

\section{Result \& Discussion}

The challenges of production and productivity in Indian mining scenario can be achieved only through adopting scientific methods of mining. To fully exploit mineral wealth of the country and to reduce imports we have to create state of art academic and scientific institutions in our country. The industry needs to be proactive in supporting development of such institutions then only slogans like Make in India can be converted to reality.

\section{Conclusion}

The number and dimension of the mining challenges are going to spiral up further. Solution lies in interdisciplinary research engagement with academia. Many issues require to be resolved at the mine level by embracing new technology (i.e., mining equipment, IT and OT integration) addressing the entire mining value chain. For routine problems, suitable tech-cells should be developed at mine/area level. Joint capacity building can be done for bridging the skill gaps.

While the academia must scale up the curriculum to include latest innovations, the industry also must provide required ambience, training facilities, support, proactive discussion forums and workshops for arriving at suitable solutions. Paid summer training under joint mentorship of academic-Industry should be thought of seriously to encourage budding engineers and scientists. Different challenges can be converted into suitable UG, PG and Ph. D projects and can be offloaded to academic institutions under active mentorship. This is seriously absent in our current system. Adequate software and instrumentation capacity must be built at subsidiary level with dedicated manpower as this is the only way to address the rising problems. 
In summary, Indian mining industry has miles to go before we realise at least a few state-of-the-art mines, ambience, technology and management to make mining profession attractive and a chosen one. It's time to raise the throttle to the peak and focus all energy in realising this dream.

\section{References}

1. Demand of Mining Industry Vis a Vis Mining Education - Bridging Gaps, Dr V M S R Murty, Dhiraj Singh, M S Tiwari, National Mining Summit on Challenges before Mining Industry for Sustainable Development, Organised by Department of Mining, VNIT, Nagpur, 22-23 September, 2014

2. Scope of Instrumentation and Automation in Indian Mining Sector, M S Tiwari, National Mining Summit on Challenges before Mining Industry for Sustainable Development, Organised by Department of Mining, VNIT, Nagpur, 22-23 September, 2014

3. Improving productivity and safety through electronics, M S Tiwari, Three day National Conference on Safety and Health Management Systems to Improve Productivity in Mines, organised by Vidarbha Productivity Council. 23-25 July, 2015, Nagpur

4. Ground control Management plan Rampura Agucha underground mine, - P. Yadav, M. Sonam, A. Panda, National Conference on Mining Equipments, New Challenges, and Applications, Organized by Indian School of Mines, Dhanbad,9-10 October, 2015,

5. Wearing Mechanism of Picks used in continuous miner machine for coal cutting, S Nahak, S Dewangan, $\mathrm{S}$ Chattopadyay, National Conference on Mining Equipments, New Challenges, and Applications, Organized by Indian School of Mines, Dhanbad,9-10 October, 2015,

6. Influence of excess burden on ground vibrations and air overpressure in open cast coal minse, M Ramulu, A K Chakraboty, N R Thote, National Summit on Emerging Trenda in Mining Technologies, VNIT, Nagpur 1-2, October, 2007

7. Base paper on Dump slope stability, I L Muthreja, National workshop on Management of dump slopes, VNIT, Nagpur, 26.12.2010

8. Rock dynamics, An over review, R K Goyal, Seminar on geotechnical challenges in infrastructure projects, organised by Central Board of Irrigation and Power, New Delhi, 25-26, April, 2013

9. The practical application of Laser scanning in mining environment, D Kruger, National Conference on Mining Equipments, New Challenges, and Applications, Organized by Indian School of Mines, Dhanbad,9-10, October, 2015

10. Instrumentation and manpower for establishment of strata / ground control cell, Prof S Jayantu, short term course on Instrumentation for evaluation of ground control problems, organized by NIT, Rourkela, 27-30, November, 2013 